\title{
Palenque superlativo: el uso de formas axiológicas en el discurso de los guías de turismo de Palenque de San Basilio*
}

\author{
Freddy David Ávila Domínguez ${ }^{1}$ \\ Universidad de Cartagena (Colombia)
}

Resumen

El presente artículo aborda el discurso de los guías de Palenque de San Basilio durante la visita guiada. Una vez que se señalan las características lingüístico-discursivas del género "exposiciones orales de los guías", se evidencia en el análisis del corpus seleccionado que, más allá de dar a conocer los contenidos de historia y cultura que identifican al destino, la narración y descripción del lugar turístico de quienes ofician como mediadores culturales responden al propósito de legitimar el propio estatus del grupo étnico, esto es, la etnicidad palenquera. El análisis de la construcción discursiva de la etnicidad palenquera en el marco de la visita guiada centra su atención en el despliegue de formas axiológicas, principalmente en la adjetivación. Esta última hace posible la exal-

\section{Abstract}

This articles explores the discourse of tour guides in Palenque de San Basilio during guided visits. Considering that tourism has a communicative dimension, this paper proposes that, more than sharing the history and culture that identify Palenque, the "tour guides's oral expositions", who act as cultural mediators, respond to the objective of legitimising the group's status, that is, the palenque ethnicity. The analysis focus on the deployment of axiological forms, specially adjectivation. We observe that adjectivation makes possible the exaltation of the tourist place and the palenqueros themselves, who find, in tourist interaction a valuable opportunity to tell -and weighdifference.

\footnotetext{
* Superlative Palenque: the use of axiological forms in the discourse of tour guides in Palenque de San Basilio

${ }^{1}$ Candidato a Doctor en Español. Investigación avanzada en Lengua y Literatura por la Universidad de Salamanca (España).e-mail: favilad@unicartagena.edu.co
} 
tación del lugar turístico y de los propios palenqueros, quienes encuentran en el escenario de la interacción turística una valiosa oportunidad para decir $-y$ ponderar- la diferencia.

Palabras clave: discurso turístico, exposiciones orales de los guías, etnicidad, construcción discursiva de identidades, formas axiológicas, adjetivación.
Key words: touristic discourse, tour guide's oral exposition, discursive construction of ethnicity, axiological forms, adjectivation, sadomasochism, trauma.

\section{Introducción}

El guía de turismo es el profesional que en la prestación de un servicio turístico informa, orienta y acompaña a turistas y visitantes en sus recorridos. "Si nos centramos en los guías, observamos que mantienen una comunicación más seguida y cuantitativamente más extensa con los clientes y en ella destaca la expresión oral. En este caso, podemos decir que el lenguaje es fundamentalmente narrativo, descriptivo y en menor medida argumentativo" (Moreno y Tuts, 2004: 1193).

Estarelación de co-presencialidad define muchas delascaracterísticas lingüístico-discursivas que se aprecian en las producciones orales de los guías. Una de ellas, tal vez la más relevante, es la apelación continua al destinatario, a quien se informa, busca, implica, estimula y persuade. El especial cuidado que se concede a la selección, organización y presentación de los contenidos, lo mismo que a la cortesía ${ }^{2}$, está al servicio de este propósito.

La atención que se presta a la imagen pública demanda la adecuación social de las palabras pronunciadas y el repertorio de gestos que las acompaña. Así, es claro que los guías deben reunir diferentes destrezas y competencias, las cuales no se limitan a lo puramente lingüístico. Moreno y Tuts (2004: 1193), al abordar la comunicación en el sector de los guías de turismo, identifican algunas de las que consideran más importantes para el ejercicio de esta labor:

\footnotetext{
${ }^{2}$ La cortesía en cualquiera de sus vertientes, esto es, como conjunto de normas sociales o como estrategia conversacional (Escandell, 2008: 142-145), está al servicio del buen funcionamiento de las relaciones sociales.
} 


\begin{tabular}{|c|c|c|c|c|}
\hline Sector & $\begin{array}{l}\text { Funciones co- } \\
\text { municativas; } \\
\text { contenidos } \\
\text { lingüísticos }\end{array}$ & $\begin{array}{l}\text { Contenidos } \\
\text { léxicos y } \\
\text { de registro }\end{array}$ & $\begin{array}{l}\text { Contenidos } \\
\text { pragmalin- } \\
\text { güísticos }\end{array}$ & $\begin{array}{l}\text { Contenidos } \\
\text { culturales }\end{array}$ \\
\hline $\begin{array}{l}\text { Guías de } \\
\text { turismo }\end{array}$ & $\begin{array}{l}\text { Saludar y des- } \\
\text { pedir, infor- } \\
\text { mar, explicar, } \\
\text { recomendar, } \\
\text { advertir, evi- } \\
\text { tar el estrés } \\
\text { cultural. } \\
\text { Contenidos } \\
\text { lingüísticos } \\
\text { propios de es- } \\
\text { tas funciones }\end{array}$ & $\begin{array}{l}\text { Registro ade- } \\
\text { cuado a las } \\
\text { característi- } \\
\text { cas del grupo; } \\
\text { léxico de la } \\
\text { descripción } \\
\text { de lugares, } \\
\text { monumentos, } \\
\text { horarios, pre- } \\
\text { cios, etc. }\end{array}$ & $\begin{array}{l}\text { Cumplir las } \\
\text { máximas de } \\
\text { Grice, contri- } \\
\text { buir a la con- } \\
\text { cordia dentro } \\
\text { del grupo, } \\
\text { evitar tér- } \\
\text { minos o } \\
\text { fórmulas que } \\
\text { refuercen } \\
\text { prejuicios, } \\
\text { mostrar aten- } \\
\text { ción e interés } \\
\text { por todos, } \\
\text { etcétera. }\end{array}$ & $\begin{array}{l}\text { Manejar co- } \\
\text { nocimientos } \\
\text { sobre las } \\
\text { diferentes } \\
\text { formas de } \\
\text { comporta- } \\
\text { miento cul- } \\
\text { tural de los } \\
\text { miembros del } \\
\text { grupo para } \\
\text { evitar cho- } \\
\text { ques con las } \\
\text { que son carac- } \\
\text { terísticas de la } \\
\text { zona visitada. }\end{array}$ \\
\hline
\end{tabular}

Fuente: Moreno y Tuts (2004).

Para estas autoras, el acompañamiento a grupos demanda destrezas relacionadas con la expresión oral y la comprensión auditiva. Su planteamiento sitúa el análisis de la comunicación de los guías de turismo en el ámbito del discurso, siendo una característica destacada del mismo su "orientación hacia al interlocutor". Esto pone en evidencia el marcado carácter subjetivo de este discurso: en atención a su carácter oral no se limita al cumplimiento de la función transaccional, sino que despliega un conjunto de elementos lingüísticos y discursivos para el cumplimiento de la función interpersonal, la cual, a diferencia de la primera, destaca que el lenguaje no sólo es "acerca de algo" sino que "hace algo en el ámbito de la interacción social" (Moreno y Tuts, 2004: 1196).

Si bien han sido poco estudiadas, en parte por su carácter efímero, las producciones orales de los guías constituyen un valioso material para dar cuenta de las narraciones y representaciones que se construyen del lugar turístico, así como de los aspectos sociales y culturales que se actualizan en la visita organizada. Calvi (2006) se refiere a ellas en términos de "las exposiciones orales de los guías" y precisa que: "hacen parte de la gran variedad géneros profesionales del turismo [...] Los géneros discursivos propios del turismo se han desarrollado más bien en la comunicación dirigida al público, tanto 
en las interacciones orales (por ejemplo, entre el guía y los turistas) como en las modalidades escritas" $(17,32)$.

\section{Discurso turístico y construcción de identidades}

Las exposiciones orales de los guías constituyen prácticas sociales y comunicativas complejas a través de las cuales se actúa para crear, mantener o transformar la(s) realidad(es). Los guías de Palenque ${ }^{3}$, como actores sociales y étnicos -esta dimensión es fundamental-, utilizan el lenguaje tanto para hablar del lugar turístico como de sí mismos. Hablar del lugar turístico equivale, de hecho, a reivindicar una etnicidad valorizada que aspira a conservar y fortalecer su estatus en el marco de la visita guiada y el país multicultural que dibujó la Constitución de 1991. Este propósito, capital en las exposiciones de los guías, sitúa al Nosotros en el centro de la actividad discursiva:

La construcción de la identidad se fundamenta en la dicotomía nosotros/ellos, e implica igualmente la percepción de características compartidas con un grupo de pertenencia frente a otros rasgos que lo diferencian de los otros miembros de otros grupos. Hay una autocategorización de la que parte el proceso de identificación, en el que los individuos atribuyen ciertas características al grupo y a los miembros del mismo, estereotipando tanto a los otros como a uno mismo (Dolón Herrero, 2012: 159).

Este Nosotros, que corresponde al "Nosotros" de los "Otros", es construido discursivamente para configurar y dotar de sentido a los dos grandes temas de las exposiciones orales de los guías: la narración de los orígenes y la descripción de los elementos representativos del patrimonio. Con ello se busca "decir la diferencia" y exaltarla.

En lo que sigue, se analizará este Nosotros tomando en consideración los recursos lingüísticos y las diferentes estrategias discursivas que lo hacen posible, en tanto no se debe entender la identidad discursiva como un atributo personal "sino como una serie de recursos que la persona puede utilizar, por tanto, como categoría con la que el usuario lingüístico actúa" (Dolón Herrero, 2012: 158).

\footnotetext{
${ }^{3}$ Palenque de San Basilio surgió hacia 1714 como resultado de los acuerdos de paz firmados por los pobladores de antiguos palenques y las autoridades coloniales de la entonces Provincia de Cartagena. En la actualidad, Palenque es considerado - de hecho, así sobrevive en el imaginario colectivo - "un rinconcito de África en Colombia". Su patrimonialización por la Unesco (2005) ha dinamizado de una manera notoria la función turística del territorio, en particular desde el etnoturismo.
} 
El corpus del análisis se halla conformado por la transcripción de las exposiciones orales de tres guías de turismo de la localidad. Estas tuvieron lugar entre 2013 y 2015, no obstante, desde 2009 se le ha venido haciendo seguimiento al discurso de los guías a través del trabajo de campo adelantado en Palenque. Esto hace que muchas de las reflexiones planteadas y los datos utilizados en el análisis estén soportadas en técnicas de investigación etnográfica.

\section{Nombres y definiciones que apelan al imaginario colectivo}

La construcción discursiva de Palenque en la visita guiada se inicia desde el primer momento en que guías de turismo y visitantes entran en contacto. Haciendo valer aquel viejo adagio de que la primera impresión es la que vale, los primeros participan en el recibimiento de los segundos, ofreciéndoles un saludo de bienvenida y presentándose como las personas que, por su condición de nativos, les ayudarán a conocer los atractivos de la localidad. Lo anterior, además de que supone un movimiento cortés, sirve para anunciar que, en adelante, tendrá lugar una relación intercultural.

La formulación del saludo en lengua palenquera, práctica habitual de algunos guías, permite escenificar la diferencia étnica. Adicionalmente, crea un ambiente propicio para la jornada: en ella tendrán relevancia, como se dijo antes, los contenidos temáticos relacionados con la historia y el patrimonio cultural de Palenque de San Basilio. Las diferentes maneras de nombrarlo y las definiciones que se hacen de él constituyen una primera aproximación a los mismos: "Es el primer pueblo libre de América, san Basilio de Palenque"; "Hoy éste es símbolo de libertad", "Palenque [...] es reconocido como el rincón de África en Colombia", "es una tierra prodigiosa, es una tierra que está abonada con algo muy importante para toda la humanidad", "es una comunidad muy importante en el contexto cultural, para Colombia, para América y el mundo", "Palenque fue escogido por la Unesco, el 25 de noviembre de noviembre del 2005, como Patrimonio oral e inmaterial de la humanidad, es una distinción muy importante".

Todas estas definiciones reproducen los significados e imaginarios que se han tejido sobre la población. Su recuperación en el marco de la visita guiada cumple una función persuasiva, en la medida que atiende los conocimientos previos y las expectativas de visitantes y turistas.

No en vano, precisamente por la carga positiva que arrastran, son también el principal gancho de los operadores turísticos 
involucrados en la comercialización del destino. La manera en que se hace referencia a Palenque de San Basilio en estos enunciados definitorios merece especial atención, en cuanto también activa significaciones asentadas en el imaginario colectivo. Para Bordonaba Zabalza (2012) la sola utilización del nombre propio, cuando éste posee fuerza de atracción, constituye en sí mismo una estrategia discursiva: "el nombre propio puede poseer una gran carga semántica y evocadora de alto rendimiento pragmático" (32).

En el corpus de estudio, los guías utilizan indistintamente Palenque y San Basilio de Palenque, nombres propios que despiertan reminiscencias históricas, relacionadas con las luchas de los esclavizados por la libertad. Su alta valorización está relacionada con el hecho de que la localidad ha pasado a ser reconocida como Primer Pueblo Libre de América. Esto lo hace un palenque sui generis, como lo recuerdan cada que vez que pueden, los guías y demás habitantes de la localidad.

La movilización permanente del vínculo con África -Palenque también es etiquetado como "Un rincón de África en el Caribe colombiano" - legitima y justifica el estatus de Palenque como localidad etnoturística, como depósito del legado ancestral de los africanos traídos al Nuevo Mundo. Los contenidos temáticos de los discursos de los guías están directamente relacionados con la reconstrucción del vínculo África-Palenque, lo cual no sólo resulta útil en términos cognoscitivos, sino en términos de la satisfacción de las expectativas de visitantes y turistas. La sola idea de vivir una experiencia de África en Colombia es tan excitante como exótica. La reconstrucción de este nexo imaginario en el marco de la visita guiada remite entonces, más que a las posibles relaciones geográficas, históricas y culturales entre ambos territorios, a una "geografía del simbolismo" (De San Eugenio, 2012).

Guías y visitantes apropian y negocian conjuntamente estas representaciones en la interacción, por medio de sus prácticas y producciones discursivas. Por su dimensión simbólica, el lugar turístico es más que un territorio al que se visita. Los guías y habitantes de Palenque parecen tenerlo claro cuando, entre las muchas maneras de nombrarlo, se refieren a él como "territorio mágico".

\section{Palenque superlativo}

El enaltecimiento de Palenque como destino etnoturístico remite a las informaciones que se ofrecen de su patrimonio cultural y 
cotidianidad. La presentación de estos contenidos temáticos les permite a los guías, atendiendo las expectativas de visitantes y turistas, decir por qué Palenque de San Basilio fue declarado Obra Maestra del Patrimonio Oral e Inmaterial de la Humanidad. Se trata, por lo tanto, de contenidos relacionados con el campo semántico del patrimonio, altamente valorados y recordados. De ahí su poder persuasivo e importancia en el desarrollo de la visita guiada.

El hecho de que los guías aborden la mayoría de estos contenidos durante los recorridos facilita su acercamiento al público, principalmente por el contacto con habitantes, prácticas culturales y espacios cotidianos. No obstante, el reducido tiempo de que se dispone y el carácter intangible de los atractivos hace del lenguaje el mejor instrumento y aliado a la hora de realizar su presentación. A través de él, los guías definen y caracterizan un conjunto de rasgos culturales que, como bien dicen ellos mismos, no se pueden tocar como a los monumentos.

Si la glorificación del pasado descansa en el uso de la narración, en este caso será la descripción la tipología más requerida. Sin embargo, confirmando el carácter híbrido de este tipo de producciones discursivas, la descripción del lugar turístico también dará cabida a otras tipologías, principalmente a la narración y a secuencias con finalidad directiva. El acoplamiento entre la descripción y la narración es bastante visible, en la medida que los guías de Palenque ofrecen detalles del destino, particularmente de sus antecedentes y rasgos culturales, relatando breves historias sobre habitantes, rituales o eventos que tuvieron lugar en la población. El campo semántico que actualiza la "tematización del espacio" (De San Eugenio, 2012) es el de lo antiguo y autóctono, asumido ahora en términos de herencia o legado.

Cualquier objeto del discurso que sea calificado, atendiendo su "denominación deorigen" como "africano" o "ancestral",lleva implícita una carga semántica positiva. Esta misma valoración se extiende al signo "palenquero", en tanto tributario de todos los rasgos positivos del vocablo "africano". La unidad léxica "palenquero", más que significar el gentilicio que designa aquello que es originario o propio de Palenque de San Basilio, connota la vigencia y el reconocimiento actual que tienen los signos culturales afropalenqueros.

Su empleo por parte de los guías y demás habitantes expresa el sentimiento de orgullo ante lo que consideran propio o característico: "Paletur es una empresa cien por ciento palenquera, cuyo capital humano es cien por ciento local, palenquero", "la cultura palenquera 
está en ojo y boca de todo el mundo", "hay dos lenguas criollas, una de esas es la de San Andrés [...] y orgullosamente la lengua palenquera", "...los dulces típicos de Palenque [...] es muy distinto el sabor cuando lo hace una palenquera genuina de Palenque, con otras que no son palenqueras", son fragmentos de discursos que ejemplifican la carga semántica positiva que arrastra el signo "palenquero". Este afán de marcar o reivindicar lo que se considera "palenquero", hace que sean recurrentes el uso de algunos adjetivos ("propio", "típico", "original"), adverbios ("propiamente", "orgullosamente") y deícticos de lugar ("aquí", "acá"). La selección léxica, en ningún caso, es inocente.

La identificación con la etnicidad valorizada a la vez que representa un motivo de orgullo, que se exhibe y ensalza, demanda esfuerzos dirigidos a su promoción y continua legitimación. Quienes ejercen el rol de guías de turismo en Palenque de San Basilio, en virtud de la implicación que tienen con el lugar, hacen de este propósito un auténtico compromiso personal. Los guías entienden que al hablar de los orígenes, los rasgos culturales o los personajes destacados de la localidad, están hablando de sí mismos y legitimando su "capital simbólico".

En Palenque, los guías se incluyen discursivamente en un nosotros étnico, por lo que la descripción turística se convierte en un pretexto para celebrar y reafirmar el estatus valorizado del grupo. En el contexto de la visita turística, el patrimonio o repertorio de rasgos culturales que definen la identidad no sólo debe ser conocido sino aceptado y compartido como tal. De ahí deriva el peso que tiene en este discurso la función pragmática de persuadir.

Los guías abordan la descripción de Palenque y su patrimonio tomando como punto de referencia los rasgos culturales reconocidos en la declaratoria de la Unesco: lengua, ritual fúnebre del Lumbalú, medicina tradicional, expresiones musicales. Estos rasgos, junto al "Kuagro", que remite a una forma de organización social soportada en la edad de los miembros del grupo, encapsulan la identidad de Palenque de San Basilio. Así lo plasma la propia declaratoria de la Unesco y el Dossier que acompañó la postulación de la candidatura.

En razón del carácter oral de las exposiciones, los conocimientos disponibles, las competencias comunicativas y el contexto de la visita guiada, las descripciones de los guías presentan variaciones significativas, en términos de la atención que se le concede a unos temas frente a otros, el orden de abordarlos o la valoración que se hace de ellos. Incluso, destaca la introducción de nuevos contenidos, 
recuperados por los guías con el propósito de hacer una presentación o descripción del lugar que resulte más atractiva.

La siguiente tabla muestra los principales temas y subtemas en torno a los cuales se configura la descripción del lugar turístico. Como se dijo antes, son abordados por los guías con bastante flexibilidad, en razón de que sus exposiciones están condicionadas por la situación de enunciación:

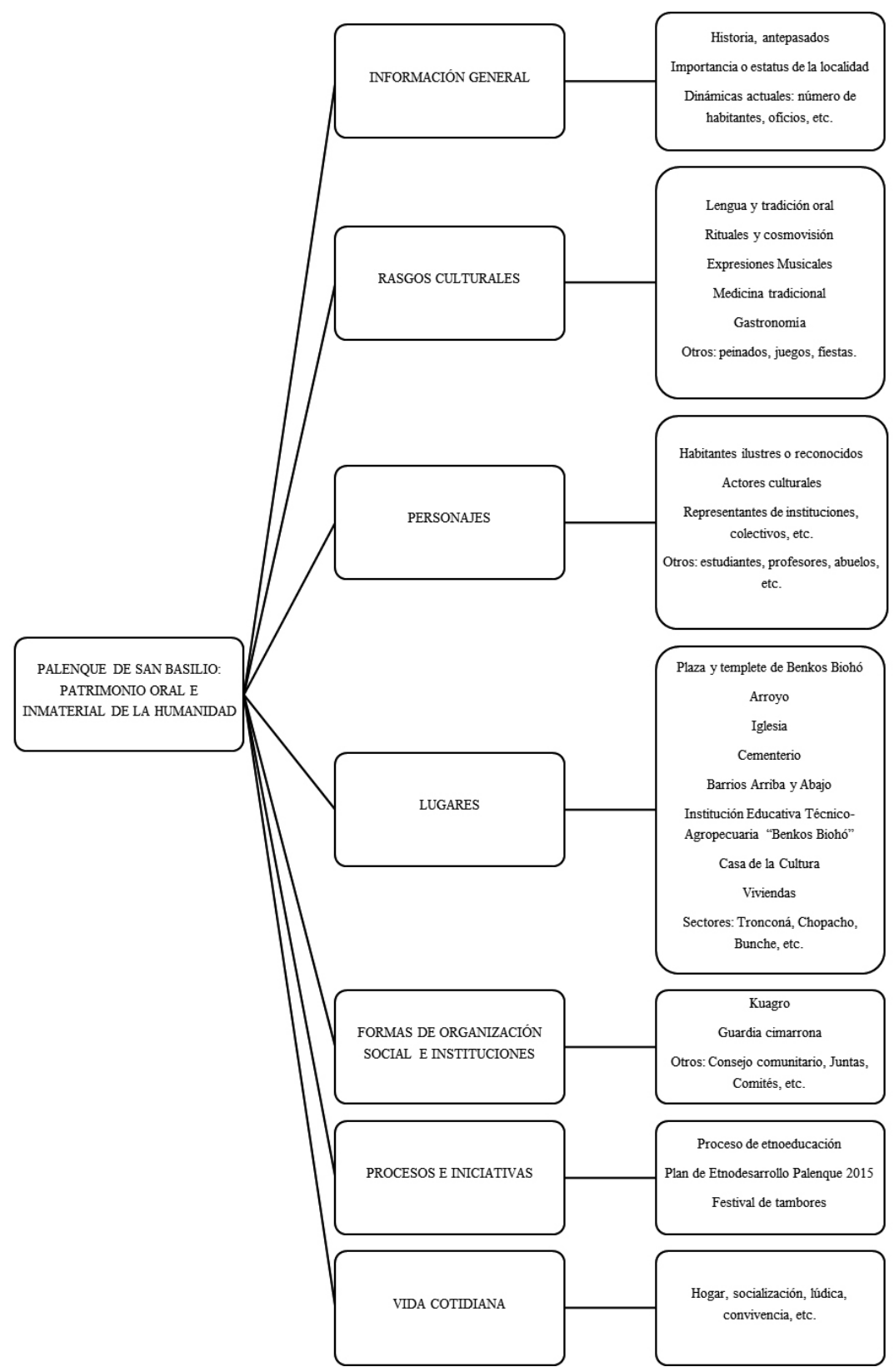


En lo que constituye una estrategia persuasiva característica del discurso publicitario, los guías dirigen la mirada hacia cada uno de estos contenidos recurriendo a diferentes expresiones evaluativas para ponderar su importancia. Su tratamiento viene precedido por un juicio de valor positivo que condiciona las interpretaciones y posteriores valoraciones de visitantes y turistas: "el primer paso para conocer nuestra comunidad es invitarlo a ese viaje mágico, a esa historia...", "hemos llegado a otro espacio que es de suma importancia para nosotros los palenqueros [...] es la calle central de la comunidad", "avancemos a la casa de uno de los maestros más representativos de la música tradicional palenquera", "ahorita vamos a hacerle una muestra de dos bailes tradicionales de la comunidad palenquera [...] cada uno de esos baile tiene un significado específico para nosotros", "toda esa ubicación de personajes de África a América, a Palenque, trae consigo unos elementos identitarios africanos y que se van a desenvolver a través de su estadía en el territorio [...] todo ese legado africano llegado acá a Palenque, está resumido en cuatro marcos muy importantes...".

La utilización de este tipo de formas axiológicas, concebidas como aquellas que definen un objeto emitiendo un juicio de valor positivo o negativo (Bordonaba Zabalza, 2012), sugiere que el tipo de descripción que destaca en las exposiciones orales de los guías no es exactamente la llamada descripción objetiva o técnica, sino la subjetiva. En esta esta última, de acuerdo con Álvarez (2010:38,39), "Lo que se describe queda mediatizado -enfatizado o minimizadopor el punto de vista del autor". En la descripción de las cualidades de Palenque y los elementos constitutivos de su patrimonio predomina el énfasis, ratificando el peso que tiene el componente subjetivo en la valoración producida.

Diferentes investigadores de los géneros discursivos del turismo han señalado la importancia de este componente. En el marco de un estudio sobre el uso de la adjetivación en la promoción de destinos turísticos, en páginas web privadas e institucionales, Nuria Edo Marzá (2012) afirma: "El uso más o menos profuso de adjetivos de un destino y la calidad de la información turística en general tendrán siempre un eminente sentido subjetivo" (51).

Los guías turísticos de Palenque de San Basilio utilizan la descripción del patrimonio para ponderar sus elementos más representativos y la misma etnicidad. La exaltación de la diferencia no sólo sirve para particularizar y hacer más atractivo el lugar turístico, sino para reafirmar la nueva posición del grupo. Así, muchas de las formas 
evaluativas son empleadas para poner de relieve a personajes de la localidad, sin importar su oficio, edad o trayectoria.

La carga semántica positiva que arrastra el nombre propio "Palenque" permea o abraza todo lo que gravita en torno suyo. Este efecto de sentido se hace extensivo a otras expresiones referenciales y deícticas que aluden a la población ("esta tierra", "comunidad", "aquí", “acá", etc.) y a África. En este último caso, la valoración está mediada por las alusiones al patrimonio ("herencia", "legado", "tradición") y a los antepasados ("ancestros", "hermanos africanos", "esclavizados", etc.).

Lo anterior pone de relieve el papel estratégico de la selección léxica en la descripción del lugar y la construcción de las realidades sociales. Para Bordonaba Zabalza (2012): “Esta operación discursiva se compone de dos mecanismos de persuasión: el primero responde al principio de credibilidad u objetividad, por el que se pretende convencer al lector de la verdad de lo dicho, y el segundo, intrínseco al proceso descriptivo, conlleva la adopción de formas evaluativas axiológicas que contienen juicios de valor" (31).

Con el propósito de refrendar durante la visita turística la vigencia y continuidad de tradiciones africanas y un pasado glorioso común, es decir aquello que le ha permitido a Palenque ser reconocido como "Un pedacito de África en Colombia" y el "Primer pueblo libre de América", respectivamente, el guía desplegará, buscando la apropiación del público que le escucha, un repertorio de estrategias léxicas y retóricas. Por su apelación al receptor, algunas de estas estrategias son prestadas al lenguaje de la publicidad.

La adjetivación y el superlativo relativo son, sin lugar a dudas, algunas de las más utilizadas. El deseo de enaltecer el lugar turístico y la identidad del grupo inscribe su uso dentro de las llamadas formas hiperbólicas. Superado el estigma (Cunin, 2003), el nuevo posicionamiento de los palenqueros pareciera dar licencia a sus miembros no sólo para "decir la diferencia", sino para encumbrarla, realizando de paso una presentación positiva de sí mismos. Así lo demuestra el siguiente análisis de las descripciones que realizan los guías. En cada recuadro se identifica el rasgo tematizado; en la primera columna aparece la estrategia o procedimiento utilizado; y finalmente, en la segunda columna, se ilustra tal estrategia con datos tomados del corpus. 


\begin{tabular}{|c|c|}
\hline \multicolumn{2}{|c|}{ RITUALES FÚNEBRES } \\
\hline $\begin{array}{l}\text { Superlativo } \\
\text { relativo, } \\
\text { adjetivación }\end{array}$ & $\begin{array}{l}\text { "En el momento del sepelio o de la velación, la } \\
\text { mamá o la pariente más cercana de la víctima } \\
\text { relata cómo su hijo murió, en lengua palenquera, } \\
\text { y los demás le responden, además también } \\
\text { algunas mujeres van cantando, otras con tambor } \\
\text { o sin tambor, sólo se vive en Palenque, eso esúnico } \\
\text { de los palenqueros y es un legado africano" }\end{array}$ \\
\hline $\begin{array}{l}\text { Expresiones } \\
\text { evocadoras, } \\
\text { enunciados } \\
\text { aseverativos para } \\
\text { particularizar } \\
\text { cualidades, } \\
\text { superlativo relativo }\end{array}$ & $\begin{array}{l}\text { "Los cantos estos son en lengua palenquera } \\
\text { [...] esos cantos no tienen traducción en } \\
\text { español, eso queda así, son los cantos del } \\
\text { muerto [...] eso es para hablarles un poco } \\
\text { del ritual del lumbalú, que es la mayor } \\
\text { tradición ancestral palenquera" }\end{array}$ \\
\hline $\begin{array}{l}\text { Caso ilustrativo a } \\
\text { partir de hipótesis, } \\
\text { Superlativo } \\
\text { relativo, enunciado } \\
\text { aseverativo, } \\
\text { adjetivación, } \\
\text { acumulación de } \\
\text { formas evaluadoras }\end{array}$ & $\begin{array}{l}\text { "Si yo me muriera hoy el velorio mío, por el hecho } \\
\text { de yo ser músico del Tabalá [...] a mí desde el día } \\
\text { en que yo me muera hasta el día de las nueve } \\
\text { noches, hay música de mi grupo ahí. Todos los días } \\
\text { la gente de mi grupo van a cantar, van a tocar en el } \\
\text { velorio. Y si ellos no están lo ponen en cinta, que } \\
\text { suene siempre la música de mi grupo. Por donde } \\
\text { va pasando el cajón con todo el desfile la gente va } \\
\text { sonando la música de mi grupo, la que me gustaba, } \\
\text { sí. Suele pasar mucho en Palenque, quiere decir } \\
\text { que en Palenque hay unos rituales muchos más } \\
\text { marcados que otros. Si la persona es un referente } \\
\text { cultural el ritual de él es mucho más apoteósico, } \\
\text { más monstruoso. Entonces es una particularidad" }\end{array}$ \\
\hline $\begin{array}{l}\text { Léxico y } \\
\text { expresiones } \\
\text { evocadoras }\end{array}$ & $\begin{array}{l}\text { "Cuando se fallece una persona es el momento, } \\
\text { digamos bandera, para expresar el entorno o la } \\
\text { cosmovisión religiosa palenquera, a través del } \\
\text { ritual Lumbalú" }\end{array}$ \\
\hline $\begin{array}{l}\text { Adverbio de } \\
\text { intensificación, } \\
\text { términos y } \\
\text { expresiones } \\
\text { culturales }\end{array}$ & $\begin{array}{l}\text { "El día de la novena noche del velorio, en eso } \\
\text { de como las doce de la noche hay un juego muy } \\
\text { significativo [...] Y es ese juego que se llama a pilá } \\
\text { el arroz" }\end{array}$ \\
\hline $\begin{array}{l}\text { Adjetivación, } \\
\text { superlativo relativo }\end{array}$ & $\begin{array}{l}\text { "El principal escenario para representar el } \\
\text { Lumbalú en la comunidad palenquera es cuando } \\
\text { fallece una persona [...] es el cuagro del difunto } \\
\text { quien se encarga de dinamizar ese velorio" }\end{array}$ \\
\hline
\end{tabular}




\begin{tabular}{|l|l|}
\hline $\begin{array}{l}\text { Exageración o } \\
\text { hipérbole }\end{array}$ & $\begin{array}{l}\text { "Cuando ya se llegó allá al cementerio, que se } \\
\text { está al frente de la bóveda, hay que destapar } \\
\text { el ataúd para que no se introduzca al revés [...] } \\
\text { que a la persona la sepulten con los pies hacia el } \\
\text { pueblo [...] no se puede hacer así, si usted lo hace } \\
\text { así, tragedia en su casa [...] como usted lo sepulta } \\
\text { con los pies pa' acá siguen los muertos o en la } \\
\text { familia o en la comunidad. Estamos pensando que } \\
\text { se enterró a alguien al revés porque últimamente } \\
\text { llevamos como dos meses de velorio todo, casi que } \\
\text { todas las semanas" }\end{array}$ \\
\hline $\begin{array}{l}\text { Adjetivación, } \\
\text { metáfora, } \\
\text { exageración o } \\
\text { hipérbole }\end{array}$ & $\begin{array}{l}\text { "El día de las nueve noches la puerta que conduce } \\
\text { hacia la calle, que conduce también hacia el patio, } \\
\text { cuando van a levantar el velorio, tienen que estar } \\
\text { despejadas sin nadien que esté por allí, porque } \\
\text { cuando ya la rezandera pone el último rezo para } \\
\text { quitar el último elemento que compone el altar, el } \\
\text { alma sale disparada el alma del difunto por allíy el } \\
\text { que esté allí, en esa puerta, lo atropella el alma del } \\
\text { difunto y se enferma. Comienza a estar sintiéndose } \\
\text { fiebre, dolor en el cuerpo y bebe pastilla y no se le } \\
\text { quita. Hay que hacerle una serie de baños y rezos } \\
\text { para que se le pueda quitar" }\end{array}$ \\
\hline
\end{tabular}

\section{MEDICINA Y REZOS}

Adjetivación, adverbios de énfasis o intensificación, exageración o hipérbole, casos o ejemplos con valor ilustrativo, comparaciones
"[...] la medicina tradicional es un legado africanoy que hoy tenemos orgullosamente a través de unos médicos propiamente palenqueros; no es que sean brujos, son médicos que han adquirido gracias a la tradición oral un conocimiento de sus abuelos, de sus tíos y lo han puesto en práctica y han curado cualquier tipo de enfermedad[...] a través de plantas, medicinas propiamente adquiridas en nuestro medio ambiente [...] hay mujeres que no puede tener hijos y hablan con Siquito, les hace un tratamiento, unos baños, unas cosas, y al poco tiempo paren hasta mellos, porque el man las pone a parir hasta mellos; habemos hombres, habemos hombres que tenemos problemas con su miembro viril y vamos $\mathrm{pa}^{\prime}$ donde Siquito y después salimos como pidiendo vía, Toyota nuevo pidiendo vía, porque ya el man nos hizo un trabajo; también hay momentos en que un niño pequeño, un niño muy pequeño le hacen afición de ojo, el médico de la academia, que está allá, centro de salud, tambalea para curar a ese pelao hasta una o dos semanas, pero lo llevas para donde Siquito y en menos de tres día el pelao está otra vez campante y sonante, como si na' hubiese pasado, porque él lo trata con medicina tradicional" 


\begin{tabular}{|l|l|}
\hline $\begin{array}{l}\text { Enunciados } \\
\text { aseverativos } \\
\text { que evocan } \\
\text { valores positivos, } \\
\text { superlativo relativo, } \\
\text { exageración o } \\
\text { hipérbole }\end{array}$ & $\begin{array}{l}\text { "La medicina no sólo cura la parte física sino la } \\
\text { espiritual, esas plantas nosotros y nosotras la } \\
\text { tenemos suave, pero hay unas que hay que ir } \\
\text { buscarlas más lejos, son para tratamientos más } \\
\text { profundos [...] entonces con plantas, con animales } \\
\text { y con rezos se curan los problemas de salud de } \\
\text { Palenque" }\end{array}$ \\
\hline $\begin{array}{l}\text { Adjetivación, } \\
\text { acumulativos }\end{array}$ & $\begin{array}{l}\text { "Papa Roma, ese señor es sabedor y conocedor de } \\
\text { la medicina tradicional" }\end{array}$ \\
\hline
\end{tabular}

\begin{tabular}{|c|c|}
\hline \multicolumn{2}{|l|}{ KUAGROS } \\
\hline $\begin{array}{l}\text { Término cultural, } \\
\text { superlativo relativo, } \\
\text { léxico con carga } \\
\text { semántica positiva }\end{array}$ & $\begin{array}{l}\text { "Aquí no hay palenquero que no tenga kuagro [...] } \\
\text { por lo general, siempre son personas del mismo } \\
\text { sector que se organizan, es como tú decir en la } \\
\text { ciudad "yo tengo mi combo", pero aquí se le da un } \\
\text { sentido más organizativo, donde a través de esa } \\
\text { estructura se dinamizan todo lo que tiene que ver } \\
\text { con las manifestaciones de acá" }\end{array}$ \\
\hline $\begin{array}{l}\text { Adverbios para } \\
\text { expresar cantidad } \\
\text { o abundancia, } \\
\text { adjetivación, } \\
\text { enunciados } \\
\text { aseverativos, } \\
\text { afirmativos y } \\
\text { negativos, para } \\
\text { expresar la cualidad } \\
\text { de perdurable }\end{array}$ & $\begin{array}{l}\text { "llega un momento en que todos los del kuagro } \\
\text { tienen la misma edad, todos, toda la gente } \\
\text { del kuagro llega un momento en el que todos } \\
\text { cumplen, tienen la misma edad, es decir, todos } \\
\text { tenemos quince años [...] es un espacio donde } \\
\text { usted puede, encuentra todo tipo de apoyo, desde } \\
\text { el apoyo espiritual hasta el apoyo económico, el } \\
\text { apoyo laboral, en fin, una serie de elementos } \\
\text { importante que ayudan mucho en tu vida. La } \\
\text { gente del kuagro que se constituye como kuagro } \\
\text { desde su juventud, nunca ese kuagro desaparece } \\
\text { hasta cuando no se muera el último. El cuadro se } \\
\text { inicia desde la crianza y eso es para toda la vida" }\end{array}$ \\
\hline $\begin{array}{l}\text { Enunciados } \\
\text { definitorios, } \\
\text { enunciados } \\
\text { aseverativos para } \\
\text { expresar una } \\
\text { cualidad de herencia } \\
\text { o tradición }\end{array}$ & $\begin{array}{l}\text { "Una vez nos asentamos en este territorio se creó } \\
\text { una organización social llamado kuagro, esos } \\
\text { kuagros, esa estructura hacedera de ese modelo } \\
\text { de organización que se tenía en el África" }\end{array}$ \\
\hline $\begin{array}{l}\text { Casos ilustrativos, } \\
\text { términos culturales }\end{array}$ & $\begin{array}{l}\text { "[...] eso eratambién un espacio defortalecimiento, } \\
\text { porque yo como kuagro, como integrante de } \\
\text { kuagro me preocupaba por poner, por jugar el } \\
\text { "Jimmy", por jugar a "La penca atrás", que son los } \\
\text { diferentes juegos de acá" }\end{array}$ \\
\hline
\end{tabular}




\begin{tabular}{|c|c|}
\hline \multicolumn{2}{|l|}{ MÚSICA Y DANZA } \\
\hline $\begin{array}{l}\text { Deixis de lugar } \\
\text { para significar } \\
\text { proximidad, } \\
\text { presentación del } \\
\text { lugar como cuna } \\
\text { de un personaje } \\
\text { ilustre o reconocido, } \\
\text { superlativo } \\
\text { relativo, empleo } \\
\text { de datos precisos } \\
\text { para aumentar } \\
\text { la sensación de } \\
\text { objetividad. }\end{array}$ & $\begin{array}{l}\text { "Aquí nació el primer cantante de champeta } \\
\text { colombiano, Viviano Torres, el primer hombre } \\
\text { que grabó la champeta en Colombia fue Viviano } \\
\text { Torres, en el año } 1986 \text { [...]" }\end{array}$ \\
\hline $\begin{array}{l}\text { Metáfora, } \\
\text { superlativo relativo, } \\
\text { caso ilustrativo, } \\
\text { exageración } \\
\text { o hipérbole, } \\
\text { presentación de } \\
\text { datos precisos } \\
\text { para aumentar } \\
\text { la sensación } \\
\text { de objetividad, } \\
\text { adjetivación. }\end{array}$ & $\begin{array}{l}\text { "[...] si yo les menciono por ejemplo un } \\
\text { cantante que está pegado, que es el segundo } \\
\text { más vendedor, que más lo solicitan, que más le } \\
\text { rayan los discos en las diferentes emisoras, como } \\
\text { Olímpica, hablando de Jhon F, se acuerdan, Jhon } \\
\text { F es palenquero [...] es el segundo cantante que } \\
\text { más vende en Cartagena, en el género champeta } \\
\text { urbana, después del hombre del serrucho, Mr. } \\
\text { Black, porque es un fenómeno" }\end{array}$ \\
\hline $\begin{array}{l}\text { Metáfora, } \\
\text { adjetivación, } \\
\text { apelación a premios } \\
\text { o reconocimientos } \\
\text { obtenidos, } \\
\text { enunciados que } \\
\text { predicen resultados. }\end{array}$ & $\begin{array}{l}\text { "Otro palenquero que está recién empacado, } \\
\text { recién ganador de los premios Shock, un } \\
\text { palenquerito que se llama Lewis. Los premios } \\
\text { Shock yo diría que es el inicio de una carrera } \\
\text { ascendente pa' este pelao" }\end{array}$ \\
\hline $\begin{array}{l}\text { Metáfora, } \\
\text { adjetivación, } \\
\text { superlativo relativo, } \\
\text { enunciados que } \\
\text { predicen } \\
\text { resultados }\end{array}$ & $\begin{array}{l}\text { "[...] otro que también viene con mucho ascenso, } \\
\text { que tiene su propia banda, ustedes lo van a } \\
\text { escuchar muy pronto, se llama Benkos Baby Set, } \\
\text { no se les olviden esos nombres [...] que van a ser } \\
\text { estrellas dentro de poco tiempo" }\end{array}$ \\
\hline $\begin{array}{l}\text { Adjetivación, léxico } \\
\text { que expresa valores } \\
\text { positivos, enunciados } \\
\text { que predicen } \\
\text { resultados, términos } \\
\text { culturales }\end{array}$ & $\begin{array}{l}\text { "Siguiendo con los héroes de la música, hay } \\
\text { también un grupo con mucha proyección en } \\
\text { Palenque y que ustedes lo van a escuchar } \\
\text { más adelante; con mucha propiedad, se llama } \\
\text { Kombilesami, música tipo palenquero" }\end{array}$ \\
\hline
\end{tabular}




\begin{tabular}{|c|c|}
\hline $\begin{array}{l}\text { Superlativo } \\
\text { relativo, adverbio } \\
\text { de intensificación, } \\
\text { léxico que expresa } \\
\text { valores positivos, } \\
\text { adjetivación. }\end{array}$ & $\begin{array}{l}\text { "Ahora el turno es para la familia más importante } \\
\text { musicalmente hablando que tiene Palenque, } \\
\text { ellos son los Batata, esa dinastía que ha sabido } \\
\text { llevar todo lo que ha sido la música propiamente } \\
\text { palenquera a diferentes lugares, a través de las } \\
\text { Alegres Ambulancias". }\end{array}$ \\
\hline $\begin{array}{l}\text { Adverbio de } \\
\text { intensificación, } \\
\text { adjetivación, } \\
\text { metáfora }\end{array}$ & $\begin{array}{l}\text { "[...] la champeta es un ritmo muy propio [...] } \\
\text { Palenque es como, trajo en los zapatos, los } \\
\text { africanos, esa música africana propiamente } \\
\text { para acá". }\end{array}$ \\
\hline $\begin{array}{l}\text { Adjetivación, } \\
\text { superlativo relativo, } \\
\text { adverbios } \\
\text { de cantidad, } \\
\text { enumeración de } \\
\text { casos ilustrativos }\end{array}$ & $\begin{array}{l}\text { "[...] la escuela de música profesional del grupo } \\
\text { Tabalá le van a hacer representación de esa } \\
\text { música tradicional [...] la música es hoy, lo más } \\
\text { fuerte, una de las más fuertes representaciones } \\
\text { de nuestro patrimonio. Porque la música se } \\
\text { encuentra inmersa en todos los espacios de la } \\
\text { comunidad palenquera; ustedes pueden ver que } \\
\text { hasta la forma en la que hablamos es cantada } \\
\text { [...] la música hace parte de nuestro diario vivir, } \\
\text { las mujeres cuando venden los dulces cantan, } \\
\text { los hombres cuando van a la rosa, a la finca, } \\
\text { cantan, nosotros cuando estamos en nuestra casa } \\
\text { cantamos, cuando estamos haciendo las labores } \\
\text { domésticas. Todo ese tipo de cosas van alrededor } \\
\text { de la música" }\end{array}$ \\
\hline $\begin{array}{l}\text { Adjetivación, } \\
\text { términos culturales, } \\
\text { enunciados que } \\
\text { contradicen } \\
\text { conocimientos } \\
\text { previos para ratificar } \\
\text { lo autóctono, } \\
\text { exageración o } \\
\text { hipérbole. }\end{array}$ & $\begin{array}{l}\text { "Ahorita vamos a hacerle una muestra dos bailes } \\
\text { tradicionales de la comunidad de San Basilio de } \\
\text { Palenque, esos bailes efectivamente son El pavo } \\
\text { y la pava y el Mapalé. Cada uno de esos bailes } \\
\text { tiene un significado específico para nosotros [...] } \\
\text { el Mapalé se cataloga como un baile de la región } \\
\text { caribe, nosotros los palenqueros lo consideramos } \\
\text { como propio, porque es que ese baile nace en ese } \\
\text { espacio, donde los negros tenían la oportunidad } \\
\text { de expresar todo a través del baile" }\end{array}$ \\
\hline
\end{tabular}

El análisis de los recursos evaluativos presentes en el discurso de los guías confirma la preeminencia de las formas hiperbólicas, particularmente del superlativo relativo y de adjetivos con valor superlativo. Su empleo, a la vez que ayuda a gestionar el intercambio, en cuanto hace atractiva las exposiciones orales, funciona a favor de la exaltación de Palenque de San Basilio. Le confiere tal grado de 
excelencia, de supremacía, que lo caracterizado supera con creces cualquier aspecto o elemento con el que se pueda comparar.

Los guías, en procura de mantener y actualizar el estatus del grupo, actúan discursivamente para poner de relieve sus rasgos prominentes. Lo hacen con tanto convencimiento e implicación que la escogencia y comunicación de las cualidades del destino riñe generalmente con la objetividad, quedando así lo descrito exaltado y/o exagerado. Los guías, como se puede ver en el corpus, utilizan para tal fin un listado reducido de adjetivos, apropiado de la comunicación cotidiana: importante(s), propio/propia(s), principal(es), primer/primero(s), mayor(es), mejor(es), gran/ grandes(s), tradicional(es), típico/típica, cultural(es), histórico/ histórica, original(es), representativo(s), ancestral(es), local, africano/africana(s), palenquero/palenquera(s), son los más frecuentes.

Este grupo de adjetivos le basta a los guías para significar la singularidad y autenticidad del patrimonio o la grandeza del mismo y de sus exponentes. Su efectividad está dada por su recurrencia, porque poseen una carga semántica positiva evidente, de gran recordación, y porque son empleados en enunciados aseverativos o comparativos. En ambos casos, su uso apunta a engrandecer el lugar turístico.

Atendiendo la clasificación antes citada de Edo Marzá (2012), estos adjetivos pertenecen, en su mayoría, a las tipologías que la investigadora denomina "Adjetivos de singularidad, originalidad y/o exclusividad", "Exaltación de lo propio" (autenticidad), "Adjetivos de popularidad" y "excelsos" (referidos a lo extraordinario). Estos últimos, en opinión de la autora, "de algún modo ya llevan implícita la marca superlativa" (76).

Esto quiere decir, confirmando la línea argumental que se ha venido exponiendo, que la descripción del lugar turístico está permeada por la subjetividad del hablante, quien en su doble condición, de guía y miembro del grupo, es "juez y parte". No es gratuito, entonces, que el grupo de adjetivos que registra menor representatividad sea el de los "Adjetivos descriptivo verificables". La presencia en el corpus de "Adjetivos objetivo-intangible" (inmaterial, cultural, ancestral) y "Adjetivos de modernidad/tradición" (antiguo/antigua, histórico/histórica) podría considerarse "esperable", en razón de los contenidos temáticos abordados. No obstante, los que llevan el peso de la caracterización del lugar son las que se han identificado arriba como más frecuentes. 
Aun así, la caracterización del lugar siempre va a más. No basta que algo sea calificado como importante, grande, mejor, único, espectacular, principal, etc., sino que se pretende, desde la subjetividad del punto de vista, que sea mucho más que eso: el/ la/lo/las más importante, grande, mejor, propicio, tradicional, espectacular, principal, etc. 0 cuando menos, si no el más importante, uno de los más importantes; si no el mayor, uno de los mayores; si no el primero, uno de los primeros: "les menciono, por ejemplo, un cantante que está pegao, que es el segundo más vendedor, que más lo solicitan, que más le rayan los discos en las emisoras [....] 'Young F', es palenquero, es el segundo cantante que más vende en Cartagena, en el género champeta urbana, después del hombre de El serrucho, 'Mr. Black'”, decía eufórico uno de los guías.

Este tipo de enunciados se repiten en el corpus seleccionado, indistintamente del rasgo cultural analizado. No obstante, es en la caracterización de los habitantes de la comunidad, en tanto exponentes de las manifestaciones que constituyen el patrimonio cultural, donde el empleo del superlativo se hace más notorio. Dado que una de las estrategias persuasivas consiste en presentar el lugar como cuna de un personaje ilustre, al nombre de Benkos Biohó, símbolo del pasado glorioso, se suma ahora un listado de nombres de nativos, fallecidos y vivos, a quienes los guías presentan como grandes líderes o héroes, en un intento por glorificar el presente de la localidad: "En Palenque han nacido grandes hombres y mujeres heroínas, y grandes personajes en toda la palabra”.

Boxeadores, actores de cine, tamboreros, cantantes, músicos, compositores, curanderos, rezanderas, bailarines, cocineros, abuelos, hablantes de la lengua, investigadores locales y habitantes del común, dedicados a los más disímiles oficios, son ensalzados. Su talento, destrezas, trayectoria y/o conocimientos son puestos en lo más alto, en los umbrales de la exageración. La descripción de los personajes suele tomar en cuenta los siguientes aspectos o elementos: nombre; año de nacimiento y muerte, si es el caso; actividad en la que destacó; inventario de su legado (títulos, grabaciones, canciones, viajes internacionales, etc.); reconocimientos.

Los nativos destacan a título individual, como miembros de agrupaciones ("En esta casa vive una señora que se llamaba Dolores Salinas, de Las Alegres Ambulancias"), o por su filiación familiar ("ella es hija de esa dinastía Batata", "[...] Graciela Salgado fue una de las tamboreras palenqueras pertenecientes a una familia de tamboreros y tamboreras acá [...] murió con ochenta y un pocotón 
de años y todavía hacía sonar su tambor [...] en esa casa también crió hijas, hijos, y todos siguieron heredando la música y la percusión").

La singularización del lugar turístico corresponde, por lo tanto, a una estrategia discursiva encaminada al establecimiento de fronteras entre "Nosotros", los palenqueros, y los "Otros". Estos podrían ser otros afrodescendientes localizados en pueblos y ciudades vecinas. Si lo palenquero es lo genuino, ¿qué calificación le corresponde a aquello que no es reconocido o no se reconoce como palenquero? La estrategia discursiva es clara: entre más se exalta al "Nosotros", mayor es su "capital simbólico" en dicha relación. Esta es la lógica que siguen las exposiciones orales de los guías.

La apropiación de todos estos reconocimientos es evidente en la promoción y comercialización actual de Palenque, y en el discurso de los guías. Lo interesante, no obstante, es ver cómo este listado se hace interminable en sus descripciones con la invención de nuevos títulos o merecimientos, que demandan una interpretación creativa de las realidades de la comunidad: "La palenquera, primera mujer emprendedora, microempresaria", "[...] hoy yo me atrevo a decir que Palenque es un corregimiento [...] que mayor profesionales tiene, y estudiantes universitarios"; "Benkos murió ahorcado en una plaza pública de Cartagena [...] ellos tenían como objetivo capturar al hombre más rebelde, al cabecilla que le ha causado más daño en América”, "[...] se chocaron con un palenque ubicado en Los Montes de María, ese fue el único o el que hasta ahora más problemas les causó; "Se está llevando a cabo el proceso de etnodesarrollo más importante de la costa Caribe colombiana y de Colombia, el proyecto de etnodesarrollo llamado Palenque 2015".

La exaltación de la localidad abarca prácticamente todos los contenidos temáticos: cimarronaje (“[...] dentro de esos asentamientos que se formaron, el único que hasta la historia la ha podido aguantar, aguantó toda esa presión, fue San Basilio de Palenque" ); etnicidad ("[...] comunidad especial, con unas características etnoraciales diferentes"); instituciones (“[...] es el único pueblo donde no hay inspección de policía [...] porque nosotros tenemos acá una organización o un modelo de gobierno tradicional"); lenguaje ("[...] uno termina refiriéndose mejor en su palenquero aquí y no tiene ningún tipo de problema"); medicina ("[...] médicos que han adquirido gracias a la tradición oral un conocimiento de sus abuelos, de sus tíos y lo han puesto en práctica y han curado cualquier tipo de enfermedad [...] a través de plantas, medicinas propiamente adquiridas en nuestro medio ambiente"); emprendimiento ("la palenquera, primera mujer emprendedora, 
microempresaria"); educación ("nosotros hemos logrado establecer dentro de Palenque un modelo educativo [...] no aplicamos una educación normal, sino una etnoeducación"); desarrollo ("Se está llevando a cabo el proyecto de etnodesarrollo más importante de la costa Caribe colombiana y de Colombia").

Todo este repertorio de significados positivos que transmiten los guías están dirigidos a visitantes y turistas, a quienes se apela a través de la comunicación de las cualidades extraordinarias, singulares, del lugar turístico. Un lugar turístico del cual, los guías son, y sobre todo, se sienten parte. El deseo de afirmar esta identidad, por todo lo que significa en términos simbólicos y prácticos, define el carácter superlativo de un discurso que siempre va a más.

\section{Bibliografía}

Álvarez Miriam. (2006). Tipos de escrito I: Narración y descripción. Madrid: Arco/Libros.

Arrázola, Roberto. (1970). Palenque, primer pueblo libre de América. Historia de las sublevaciones de los esclavos de Cartagena. Cartagena: Ediciones Hernández.

Ávila Domínguez, Freddy. (2011). "Lo 'afro' en el discurso turístico de Cartagena: subexposición y sobreexposción". En Freddy Ávila, Ricardo Pérez Montfort \& Christian Rinaudo (coords.). Circulaciones Culturales. Lo afrocaribeño entre Cartagena, Veracruz y La Habana. México: Publicaciones de la Casa Chata, pp. 189-216.

Barth, Frederick. (Comp.). (1976). Los grupos étnicos y sus fronteras. La organización social de las diferencias culturales. Introducción. FEC: México D.F., pp. 9-49.

Calsamiglia, Helena y Amparo Tusón (1999), Las cosas del decir. Manual de análisis del discurso. Barcelona: Ariel.

Calvi, MaríaVittoria. (2006). Lengua y comunicación en el español del turismo. Madrid: Arco/Libros.

Calvi, M.V., Bordanaba, C., Mapelli, Giovanna \& Lantos, Javier. (Eds.) (2009), Las Lenguas de especialidad en español. Roma: Carroci.

Covadonga López, Alonso. (2014). Análisis del discurso. Madrid: Síntesis.

Cunin, Elisabeth. (2003).Identidades aflor depiel. Lo "negro" entreapariencias y pertenencias: categorías raciales y mestizaje en Cartagena (Colombia). Bogotá: Instituto Colombiano de Antropología e Historia-Universidad de los Andes-Instituto Francés de Estudios Andinos-Observatorio del Caribe Colombiano.

De San Eugenio, Jordi. (2012). "Aproximaciones teóricas y conceptuales para una definición del estado del arte de la comunicación de los destinos turísticos", Andamios, vol. IX, no 20, pp. 211-236. 
Dijk, Teun A. Van. (comp.) (2000). El discurso como estructura y proceso. Estudios sobre el Discurso I: introducción multidisciplinaria, Barcelona, Gedisa.

Dolón Herrero, Rosana. (2012). "El niño como actor social en el discurso turístico: un estudio de análisis crítico de la construcción discursiva de una identidad de consumidor". En San Martín Sáez, Julia. (Ed.). Discurso turístico e internet. Madrid: IberoamericanaVervuert, pp. 155-186.

Friedemann, Nina \& Cross, Richard. (1987 [1979]). Mangombe. Guerreros y ganaderos en Palenque. Bogotá: Carlos Valencia Editores.

Hall, Stuart. (1991). "The local and the global: globalization and ethnicity". En Anthony King. (Ed.). Culture, Globalization and the WorldSystem. London: Macmillan, pp. 19-40.

Moreno García, Concha \& Martina Tuts. (2004), "La enseñanza del español del turismo". En Sánchez Lobato \& Santos Gargallo. [Eds.], pp.1185-1204.

Obeso, Kandia. (2013). Turismo, Patrimonio y etnicidad: dinámicas del turismo étnico cultural en San Basilio de Palenque. Tesis de Grado para optar al título de Magíster en Desarrollo y Cultura. Universidad Tecnológica de Bolívar, Cartagena. 
